\title{
Expansão da produção da cana-de-açúcar no Mato Grosso do Sul: uma análise do modelo shift-share
}

\author{
Josiane Araújo Verão* \\ Jaqueline Severino da Costa** \\ Rafael Forest ${ }^{* * *}$
}

\section{Resumo}

As novas perspectivas para o etanol e o aumento do consumo de açúcar no mundo levaram a uma considerável expansão na produção de cana-de-açúcar. Nesse sentido, o objetivo deste artigo é analisar a expansão da produção da cana no estado do Mato Grosso do Sul, Brasil, entre 1990 e 2011. O método utilizado foi o shift-share. Os resultados mostram que a principal causa da expansão da produção de cana-de-açúcar no estado foi o efeito área. $\mathrm{O}$ efeito substituição apresentou valor positivo para a cultura da cana-de-açúcar, confirmando que a cultura ganhou espaço dentro do estado. $\mathrm{O}$ efeito produtividade mantevese próximo a zero, não indicando grandes ganhos de produtividade. $\mathrm{O}$ efeito localização geográfica apresentou uma tendência decrescente, indicando que não houve mudança na localização das lavouras de cana-de-açúcar.

Palauras-chave: Cana-de-açúcar. Expansão produtiva. Mato Grosso do Sul. Shift-share.

* Acadêmico de Ciências Econômicas da Faculdade de Administração, Ciências Contábeis e Ciências Econômicas da Universidade Federal da Grande Dourados. E-mail: josi_verao@hotmail.com

** Doutora em Economia Aplicada pela Universidade de São Paulo. Professora da Faculdade de Administração, Ciências Contábeis e Ciências Econômicas da Universidade Federal da Grande Dourados. E-mail: jaquelinecosta@ufgd.edu.br

**** Mestre em Agronegócios pela Universidade Federal da Grande Dourados. Professor na Universidade Estadual de Mato Grosso do Sul e nas Faculdades FIP/Magsul. E-mail: rafael_forest@hotmail.com

http://dx.doi.org/10.5335/rtee.v22i46.6755

Submissão: 24/04/2015. Aceite: 04/04/2016. 


\section{Introdução}

O setor sucroenergético brasileiro contava em 2012 com 430 unidades produtoras, cerca de 70 mil produtores de cana-de-açúcar, gerando um total de 1,2 milhões de empregos diretos. A cana-de-açúcar ainda registrou um PIB de US $\$ 48$ bilhões e US $\$ 15$ bilhões em exportações (UNIÃO DA INDÚSTRIA DE CANA-DE-AÇÚCAR, 2012).

De acordo com os dados da União da Indústria da Cana-de-açúcar (Unica), o Brasil é atualmente o maior produtor de cana-de-açúcar do mundo. $\mathrm{O}$ país produz mais de 490 milhões de toneladas de cana-de-açúcar por ano (safra 2011/2012) e registra 9,6 milhões de hectares de área plantada com a cultura. O Brasil é também o primeiro produtor mundial de açúcar, responsável por $25 \%$ da produção mundial e $50 \%$ das exportações mundiais. O país ocupa, hoje, a segunda posição na produção de etanol, atrás somente dos Estados Unidos da América, sendo responsável por $20 \%$ da produção mundial e por $20 \%$ das exportações mundiais.

De acordo com dados da Secretaria de Relações Internacionais do Agronegócio, o complexo sucroalcooleiro ocupou o terceiro lugar nas exportações brasileiras em 2012, perdendo apenas para o complexo soja e as carnes (US $\$ 15,64$ bilhões), com participação de US $\$ 15,42$ bilhões.

Ferreira Neto (2005) acrescenta que o país possui outras vantagens, como os custos de produção, em que é o mais competitivo. Ainda, pode-se citar grande disponibilidade de terras adequadas ao plantio, tecnologia agrícola e industrial, escala de produção e clima favorável. Quanto à questão climática, vale ressaltar que é o que permite de cinco a seis vezes colheitas antes de novo plantio, representando uma vantagem em relação a outros países, como a Índia, por exemplo, onde, em média, a cana-de-açúcar necessita ser replantada a cada duas ou três colheitas.

Projeções feitas pelo Ministério da Agricultura, Pecuária e Abastecimento (BRASIL, 2008) apontam que o Brasil será, em pouco tempo, o principal polo mundial de produção de biocombustíveis a partir de cana-de-açúcar e óleos vegetais, com destaque para a liderança na ocupação de novas áreas com cana-de-açúcar, cujo aumento esperado é de cerca de $66 \%$ em área plantada até 2017.

A Região Centro-Sul representa mais de $80 \%$ da produção de cana-de-açúcar no Brasil. Nesse contexto, o estado do Mato Grosso do Sul destaca-se pela gradativa expansão no setor nos últimos anos. Atualmente, o estado é o quinto maior produtor de cana-de-açúcar do Brasil. O aumento gradativo da importância econômica da cana-de-açúcar no Mato grosso do Sul colocou em evidência a preocupação com a segurança alimentar no estado, que é referência na produção de soja, milho, arroz e feijão, além de ter como principal atividade a pecuária (FOREST et al., 2014). 
Dada a importância do setor sucroenergético no contexto agroeconômico brasileiro e sul-mato-grossense e sua expansão de forma acelerada nos últimos anos, esta pesquisa tem como objetivo verificar se houve maior ampliação no cultivo da cana-de-açúcar frente às demais culturas do Mato Grosso do Sul.

\section{Revisão bibliográfica}

A importância econômica da cana-de-açúcar decorre dos seus mais diversos usos. Planta alternativa por excelência, ela não apenas constitui matéria-prima para fabricação do açúcar, mas dá origem também a numerosos derivados e subprodutos, todos de grande utilidade - como o melaço, o álcool, a aguardente, o fermento para panificação, a celulose, a proteína para rações, os fertilizantes, etc. (SZMRECSÁNYI, 1979).

O setor sucroenergético, dentro do complexo agroindustrial brasileiro, foi um dos que sofreu a maior e mais prolongada intervenção governamental. O Instituto do Açúcar e do Álcool (IAA), criado em 1933, foi o principal órgão gestor do setor sucroalcooleiro. Suas funções eram administrar e propiciar seu desenvolvimento além de estabelecer as quotas de produção e os preços da cana, do açúcar e do álcool (MARJOTTA-MAISTRO, 2002).

A criação do IAA sujeitou o produtor da agroindústria canavieira a uma série de arranjos institucionais que vinculavam os interesses organizados do setor às estruturas de decisão do Estado. Desse modo, com expedientes como a garantia de margens de lucro, reserva de mercado, concessão de subsídios, entre outros, a intervenção do Estado contribui para arrefecer o surgimento de um ambiente competitivo na agroindústria canavieira (MORAES; SHIKIDA, 2002).

Em 1973, os preços internacionais do petróleo aumentaram em cerca de $428 \%$, resultando no primeiro choque do petróleo mundial. Com uma necessidade de $80 \%$ de petróleo externo, o governo brasileiro viu-se obrigado a buscar alternativas ao consumo de combustível no país, resultando disso a criação do Programa Nacional do Álcool (Proálcool) em 1975 (MICHELLON; SANTOS; RODRIGUES, 2008).

O Proálcool estabelecia metas de expansão da produção de álcool no país. Na sua primeira fase, a meta estabelecia que a produção passasse de 500 milhões para 3 bilhões de litros de álcool por ano (BACHA, 2012). Apesar de um aumento de $300 \%$ na produção de álcool ainda na primeira fase do programa, foi em sua segunda fase que o Próalcool atingiu seu auge de expansão, e também o início de seu declínio, em meados de 1985. O governo atingira seu objetivo, consolidar o programa como alternativa à substituição de energia (SHIKIDA; BACHA, 1999). 
Segundo Silva (2006), no final dessa fase, o preço do petróleo começa a tender à estabilidade, o mercado de açúcar estava em ascendência e a realidade econômica do país era crítica, resultado de uma crescente deterioração das condições econômicas e sociais do país. Portanto, houve uma redução dos investimentos em torno do programa a partir de 1985.

A partir da década de 1990, o Proálcool passou a apresentar um perfil diferente daquele verificado no início de sua implantação. As novas medidas econômicas, que levaram à desregulamentação do setor, também impactaram o programa, que deixou de ser incentivado de maneira tão intensa como antes (MARJOTTA-MAISTRO, 2002).

Até a década de 1980, a agroindústria canavieira crescera sob o amparo do Estado. Isso fez com que várias empresas pouco se preocupassem com a produtividade, atuando dentro de um paradigma subvencionista (BACHA, 2012).

A desregulamentação do setor sucroalcooleiro faz parte de um processo mais amplo de afastamento do Estado da economia brasileira, iniciado no governo Collor. A crise enfrentada pelo país desde os anos 1980 reduziu a capacidade de atuação do Estado - como coordenador ou indutor da atividade econômica -, fazendo emergir um processo de liberações e de privatizações de importantes setores da economia, a partir de meados dos anos 1990, após a extinção do IAA (MORAES; SHIKIDA, 2002). Esse fator foi acompanhado da gradativa liberação dos preços dos produtos do setor.

Após a liberação de comércio, vários grupos estrangeiros realizaram aporte significativo em grandes projetos de usinas, consequentemente, o setor sucroalcooleiro brasileiro desenvolve-se de forma acelerada nos últimos anos, resultado da crescente demanda por fontes de energia limpas e sustentáveis. Atualmente, o país conta com cerca de 430 usinas que produzem açúcar e álcool (UNICA, 2011).

Os debates sobre os problemas ambientais trouxeram uma nova perspectiva para a produção de cana-de-açúcar no século XXI. A busca por fontes de energia renováveis colocou o etanol combustível em posição de destaque na economia mundial. Os biocombustíveis, principalmente o etanol, são fontes energéticas que apresentam melhores atributos ambientais, sociais, econômicos e estratégicos em relação aos derivados de petróleo. Na época atual, esse modelo energético, já consolidado no Brasil, está servindo de referência para vários países (THEODORO, 2011).

A criação dos veículos flexfuel, em 2003, também favoreceu a expansão da produção canavieira. Segundo dados da Unica, a venda de veículos flex passou de 48.178, em 2003, para 3.162.822, em 2012. Em contrapartida, houve uma queda de 
420,56\% na venda de veículos movidos somente a gasolina, e os veículos somente a álcool hidratado saíram do mercado, muito em virtude de a opção pelo combustível a ser utilizado ser feita na hora do abastecimento, e não no momento da aquisição do veículo.

As exportações do agronegócio, em 2006, totalizaram US\$ 49,4 bilhões, um recorde histórico para o setor. Entre os fatores que explicam o desempenho positivo do agronegócio, destaca-se o elevado crescimento da economia mundial, que implicou em maior demanda por bens e aumento dos preços de importantes commodities da pauta de exportação, como açúcar e álcool, café e carnes (MENDES; PADILHA JÚNIOR, 2007).

Em 1994, o açúcar foi responsável, em média, por 5\% do valor total exportado pelo Brasil. Em 2000, esse número foi de 3,5\%, já em 2009, de 5,5\% das exportações brasileiras. Já o álcool é destinado, em grande parte, ao consumo interno. As exportações de álcool representaram 0,6\% das exportações brasileiras em 2005, e 1,2\% em 2008 (BACHA, 2012).

Tendo em vista o grande potencial brasileiro para exportação de etanol, associado à grande demanda mundial e interna para o produto, o cenário que desponta é de um aumento ainda maior em área plantada de cana-de-açúcar. $\mathrm{O}$ que poderia ser um contraponto a esse panorama seria a descoberta de uma fonte energética automotiva mais promissora do que o etanol, o que parece ser muito improvável em curto prazo (THEODORO, 2011).

É importante destacar que o Brasil ainda é o único país produtor de açúcar que também produz álcool combustível em escala industrial, embora outros países já estejam iniciando pesquisas para desenvolver um parque industrial alcooleiro. O desenvolvimento do uso de álcool combustível em outros países não somente abriria mercado para o produto nacional, como também criaria um mercado internacional de álcool (MORAES; SHIKIDA, 2002).

Até o final de 2006, na Região Centro-Sul, existiam 200 usinas e destilarias cadastradas no Ministério de Agricultura, Pecuária e Abastecimento (Mapa). Entre janeiro de 2007 e junho de 2010, mais 147 unidades agroindustriais foram cadastradas na região pelo Mapa (BACCARIN; GEBARA; BORGES JÚNIOR, 2011). Segundo Mendes e Padilha Júnior (2007), a área destinada à cultura da cana-de-açúcar, em 2007, era de 5,3 milhões de hectares no Brasil, estando atrás somente das culturas de soja (17,8 milhões de hectares) e de milho (12,1 milhões de hectares). Entre as culturas agrícolas produzidas no Brasil, a cana-de-açúcar ocupa o terceiro lugar em relação à área plantada, ficando atrás da soja, com 23,468 milhões de hectares, e do milho, com 12,994 milhões de hectares, dados das safras 
2009/2010, o que faz o Brasil ser considerado o maior produtor mundial de cana-de-açúcar (COMPANHIA NACIONAL DE ABASTECIMENTO, 2011).

De acordo com relatório de safras da Companhia Nacional de Abastecimento (Conab) de 2013, na safra 2012/2013, a Região Centro-Sul, em relação à cultura de cana-de-açúcar, deveria ter um incremento de 489,34 mil hectares, um provável incremento de $17,91 \%$. Os estados com maiores áreas de expansão devem ser São Paulo, Goiás, Minas Gerais, Paraná e Mato Grosso do Sul.

No Levantamento Sistemático da Produção Agrícola, de fevereiro de 2013, realizado pelo Instituto Brasileiro de Geografia e Estatística, a produção de cana-de-açúcar obteve um crescimento na produção de 3,2\%, comparando-se com a produção no mês anterior. Esse crescimento foi composto por um aumento de 5,6\% na área a ser colhida, com uma redução de 2,3\% no rendimento médio. Essas alterações foram observadas, principalmente, nos estados de São Paulo e Mato Grosso do Sul, com acréscimos de $11,2 \%$ e $9,1 \%$, respectivamente, na área a ser colhida, e com reduções de $4,3 \%$ e $3,1 \%$ no rendimento médio, respectivamente.

$\mathrm{O}$ estado de Mato Grosso do Sul aparece em destaque nas atividades agroindustriais por estar localizado estrategicamente entre mercados potenciais, como o Mercado Comum do Sul e os grandes centros consumidores brasileiros. Além disso, seu potencial de recursos naturais e a infraestrutura moderna voltada para o apoio ao setor produtivo alavancam investimentos no desenvolvimento de atividades agroindustriais e de expansão do intercâmbio comercial (GUIMARÃES; TURETTA; COUTINHO, 2010).

A cana ocupa cerca de 450 mil hectares no Mato Grosso do Sul e há a possibilidade de que essa área possa aumentar em até vinte vezes, sem prejuízo da produção de alimentos. Isso chegaria a 8 milhões de hectares, em terras que, no momento, são utilizadas como pastagens subaproveitadas para pecuária. Com as novas técnicas de criação de gado, a pecuária pode aumentar sua produtividade e diminuir o uso da terra, que então fica livre para a cultura da cana (BIOSUL, 2012).

A expansão produtiva da cana-de-açúcar tornou-se base para o crescimento regional do estado do Mato Grosso do Sul, contribuindo para o aumento de empregos diretos e indiretos, além de especializar grande parte da mão de obra da região.

$\mathrm{O}$ crescimento regional é impulsionado tanto por fatores internos como por fatores externos à região. Entre os vários métodos da análise regional (SIMÕES, 2005), o método estrutural-diferencial (ou método shift-share) pode ser utilizado para captar esse comportamento da dinâmica regional. Originalmente, desde o seu desenvolvimento, o método estrutural-diferencial é o mais indicado para a análise do emprego, em especial emprego industrial. Entretanto, principalmente depois dos últimos 
desenvolvimentos metodológicos, passou a ser aplicado em uma ampla área de estudos, contribuindo para os mais distintos objetivos acadêmicos (GALETE, 2011).

Desenvolvido por Dunn em 1960 para análise da alteração das variáveis setoriais e regionais em relação à mudança das mesmas variáveis em uma ampla magnitude, trata-se de um modelo descritivo para quantificar mudanças ocorridas em determinados períodos (PADRÃO; GOMES; GARCIA, 2012).

Segundo Simões (2005), o método shift-share consiste, basicamente, na descrição do crescimento econômico de uma região nos termos da sua estrutura produtiva. Estrutura-se a partir de um conjunto de identidades - com quaisquer hipóteses de causalidade - que procuram identificar e desagregar componentes de tal crescimento, em uma análise descritiva da estrutura produtiva.

\section{Metodologia}

\subsection{Dados utilizados}

Os dados sobre a cana-de-açúcar são oriundos dos relatórios finais de safras da Unica para o período de 1990/1991 a 2011/2012. Serão utilizados também os dados da Conab das séries históricas de safras de soja, milho e outros produtos (arroz e feijão).

\subsection{Método}

O método utilizado para verificar a expansão da produção da cana-de-açúcar no mercado sul-mato-grossense será o shift-share, ou diferencial-estrutural. Para Dunn, criador do método, a principal característica considerada no método shift-share deve ser a localização geográfica, por identificar vantagens comparativas na produção de determinados produtos (PADRÃO; GOMES; GARCIA, 2012 ).

A produção de um produto $j$ no ano $t$, em uma série temporal, pode ser dada pela seguinte equação:

$$
\mathrm{Q}_{\mathrm{jt}}=\sum \mathrm{a}_{\mathrm{ijt}} \cdot \mathrm{A}_{\mathrm{it}} \cdot \mathrm{P}_{\mathrm{ijt}}
$$

Em que: $a_{i j}$ é a participação (em \%) da produção da cultura $j$, na produção total do estado $i$ (Mato Grosso do Sul); $\mathrm{A}_{\mathrm{i}}$ é a área colhida no estado $i$ (Mato Grosso do $\mathrm{Sul}$ ); $\mathrm{P}_{\mathrm{ij}}$ é a produtividade (tonelada/hectare) das lavouras $j$ (cana, soja, milho) no estado $i$. 
No ano imediatamente anterior, a produção é dada por:

$$
Q_{t-1}=\Sigma a_{i j t-1} \cdot A_{i t-1} \cdot P_{i j t-1}
$$

Na equação 2, se somente a área variar entre o ano t-1 e o ano $t$, a quantidade produzida será:

$$
Q_{t a}=\Sigma a_{i j t-1} \cdot A_{i t} \cdot P_{i j t-1}
$$

Se, além da área, a produtividade também variar, entre o ano $t$ - 1 e $o$ ano $t$, a quantidade produzida será:

$$
Q_{t p}=\Sigma a_{i j t-1} \cdot A_{i t} \cdot P_{i j t}
$$

Dessa forma, a produção nacional terá uma variação total $\left(Q_{t}-Q_{t-1}\right)$ que pode ser decomposta em três efeitos, quais sejam:

Efeito área (EA):

$$
Q_{t a}-Q_{t-1}
$$

O efeito área pode ser decomposto em dois efeitos, resultando no efeito escala e no efeito substituição:

$$
A_{j t}-A_{j 0}=\left(y A_{j 0}-A_{j 0}\right)
$$

Efeito substituição (ES):

$$
A_{j t}-y A_{j 0}
$$

Efeito escala (EE):

$$
y A_{j 0}-A_{j 0}
$$

Em que $y$ é o coeficiente que mede a modificação na área total produzida (AT):

$$
y=A T_{t}-A T_{0}
$$

$\mathrm{t}=t$ período final $\quad \mathrm{t}=0$ período inicial

$$
\begin{array}{ll}
\text { Efeito produtividade (EP): } & Q_{t p}-Q_{t a} \\
\text { Efeito localização geográfica (ELG): } & Q_{t}-Q_{t p}
\end{array}
$$




\section{Resultados e discussão}

A expansão na produção de cana-de-açúcar no Mato Grosso do Sul é analisada por meio do método shift-share para as safras de 1990/1991 a 2011/2012. O método permitirá a análise das alterações na produção de cana-de-açúcar resultantes de incrementos na área plantada, da produtividade e da localização das lavouras na cultura no Mato Grosso do Sul.

É possível verificar, a partir da Figura 1, que a expansão da produção da cana-de-açúcar no Mato Grosso do Sul, nos anos de 1990 a 2011, ocorreu em maior magnitude que nas demais culturas agrícolas no estado.

Figura 1 - Produção total das culturas agrícolas no Mato Grosso do Sul, safras de 1990/1991 a 2011/2012 (em milhões de toneladas)

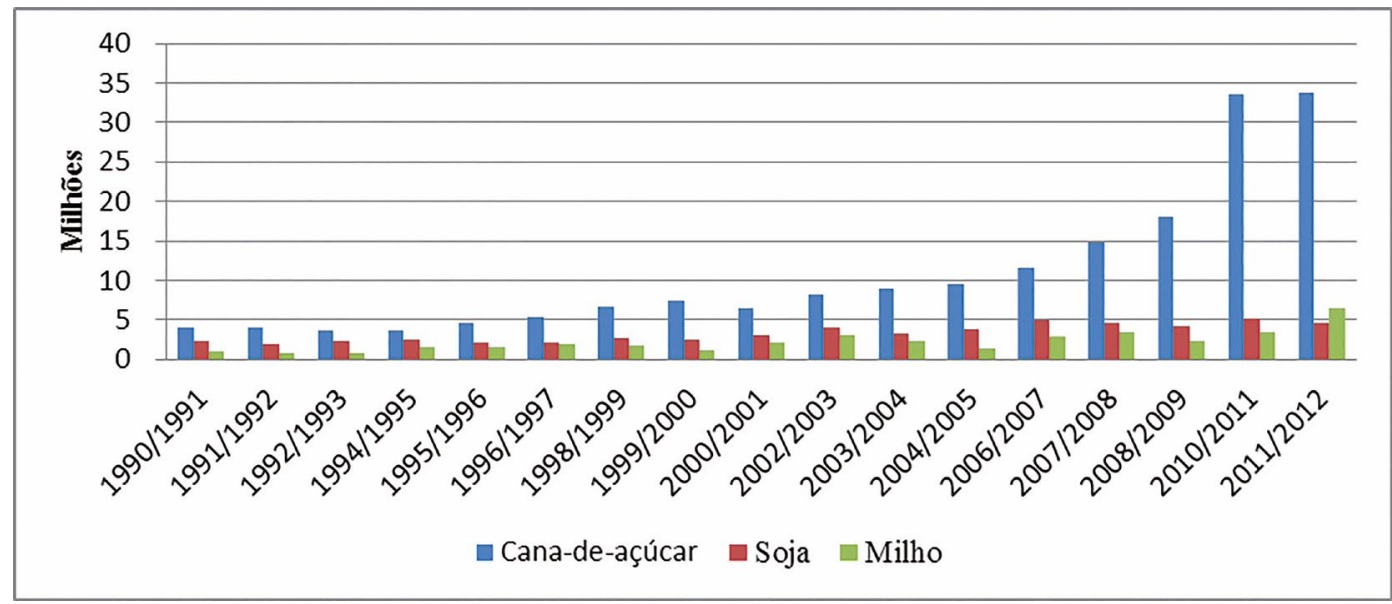

Fonte: elaborada pelos autores com base em dados da Conab.

O Mato Grosso do Sul aumentou sua produção de cana-de-açúcar em mais de $750 \%$, passando de 3,7 para 33,86 milhões de toneladas, no período observado. Outro destaque foi na produção de milho, que contou com um aumento de 585\%. A soja dobrou sua produção de 1990 a 2011, saindo de 2,3, em 1990, para 4,62 milhões de toneladas, em 2011. Dentre as culturas analisadas, somente as produções de feijão e arroz decresceram nesse período, resultando em uma queda de $80 \%$ no seu total produzido, não aparecem na Figura 1 porque a produção não alcançou 200 mil toneladas.

Observa-se também que a produção de cana-de-açúcar no Mato Grosso do Sul cresceu lentamente até a safra 2006/2007. Após esse período, contou com um 
aumento expressivo, que pode ser atribuído à perspectiva favorável dos combustíveis renováveis no século XXI, dentre eles o etanol, que traçou uma nova dinâmica para o setor sucroenergético, resultando na expansão da produção de cana-de-açúcar em todo o estado (Figura 1).

A expansão da produção da cana-de-açúcar levou a discussões sobre uma possível substituição das áreas destinadas às demais culturas, como a soja e o milho, porém, o que se observa é que essas culturas também obtiveram crescimento significativo em suas áreas plantadas. A área destinada à produção da soja no Brasil aumentou em 53\% de 2000 a 2011, enquanto que a área destinada à produção de milho teve aumento de $15 \%$ no mesmo período (Figura 1).

Conforme se observa na Figura 2, no Mato Grosso do Sul, as áreas destinadas ao cultivo da cana-de-açúcar são inferiores às das demais culturas, embora tenham aumentado em mais de $600 \%$ de 1990 a 2011 . A soja, que ocupa a maior área de plantio, teve um acréscimo de apenas $79 \%$, enquanto o milho contou com um incremento de $252 \%$ no mesmo período.

Figura 2 - Área total das principais culturas agrícolas no Mato Grosso do Sul das safras de 1990/1991 a 2011/2012 (em milhões de hectares)

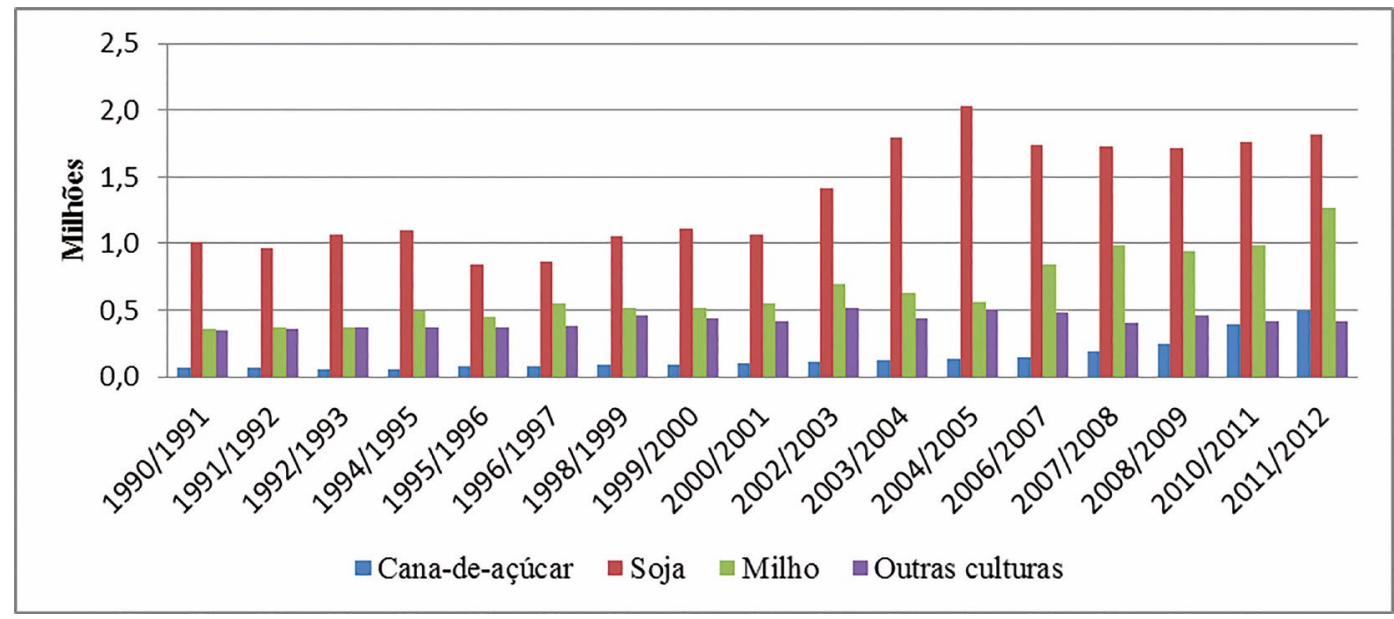

Fonte: elaborada pelos autores com base em dados da Conab.

Em 2011, a cana-de-açúcar ocupava um total de 9,6 milhões de hectares cultivados no Brasil, desse total, 495 mil hectares de área plantada com a cultura estava no Mato Grosso do Sul. Segundo dados da Federação da Agricultura e Pecuária do Mato Grosso do Sul (2013), a cana-de-açúcar ocupa 2,3\% das terras 
sul-mato-grossenses, perdendo apenas para a soja na safra verão, que ocupa um total de 5,5\% da área total do estado, e para o milho com 4,4\% de área, na safrinha.

Figura 3 - Produtividade da cana-de-açúcar no Mato Grosso do Sul entre 1990/1991 e 2011/2012 (em milhões de toneladas)

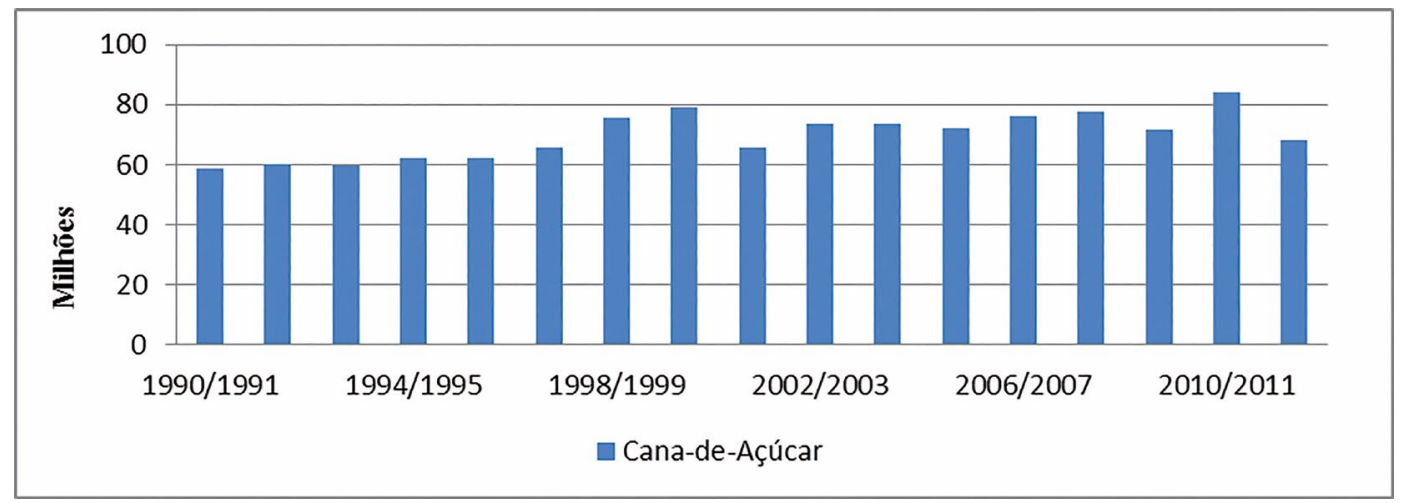

Fonte: elaborada pelos autores com base em dados da Conab.

Os picos negativos, observados na Figura 4, referem-se às quebras de safra resultantes da sazonalidade das culturas agrícolas, em especial, das chuvas inesperadas ou de baixas precipitações (CONAB, 2013). Apesar de apresentar índices negativos, a produtividade da cana-de-açúcar aumentou em $16 \%$ no período. Para a soja, os ganhos de produtividade chegaram a $12 \%$. O grande destaque da análise foi o milho, que aumentou em $94 \%$ sua produtividade no período analisado.

Figura 4 - Produtividade das culturas agrícolas no Mato Grosso do Sul das safras de 1990/1991 a 2011/2012 (em milhões de toneladas)

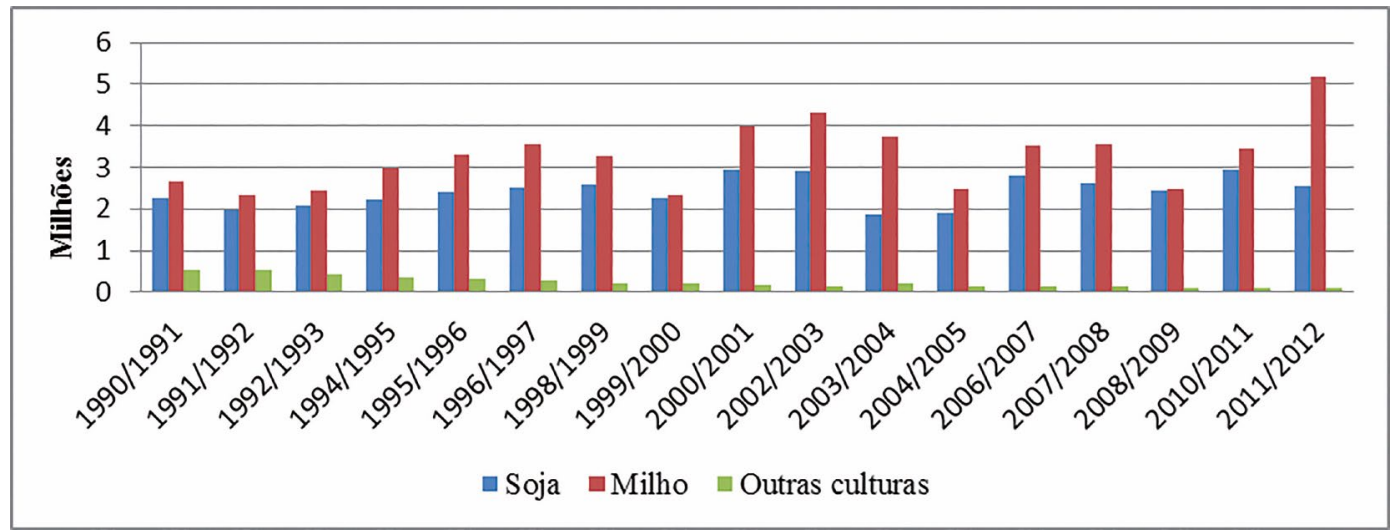

Fonte: elaborada pelos autores com base em dados da Conab. 
A análise dos efeitos área, produtividade e localização geográfica do método de análise shift-share pode ser observada na Figura 5. O efeito área foi o que apresentou maior crescimento com relação aos demais, demonstrando que a expansão na produção de cana-de-açúcar no estado contou com um significativo incremento em suas áreas plantadas.

Figura 5 - Evolução dos efeitos área, produtividade e localização geográfica nas safras de canade-açúcar de 1990/1991 a 2011/2012

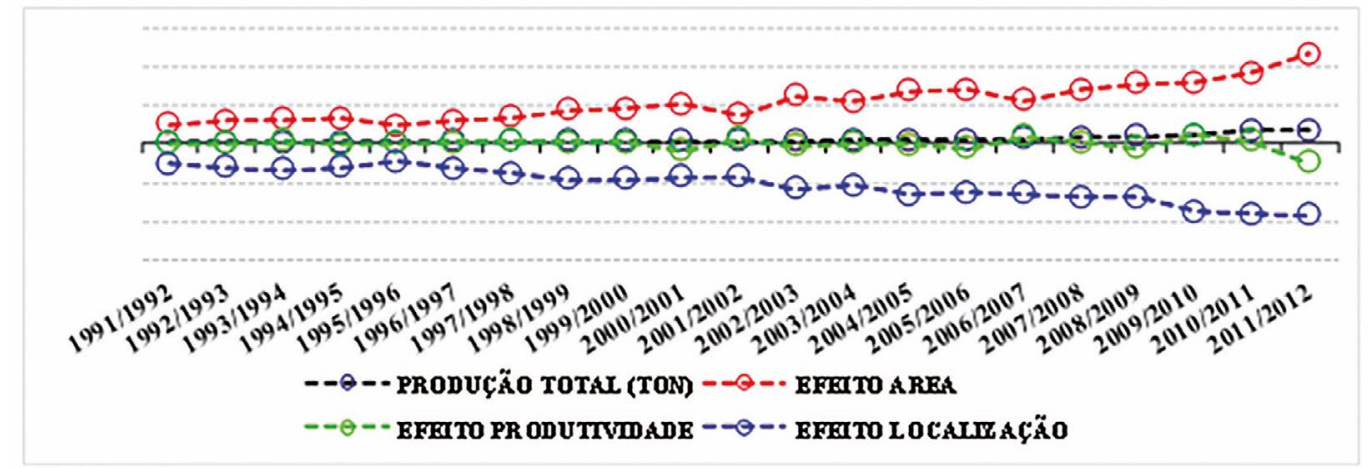

Fonte: elaborada pelos autores com base em dados da Conab.

O efeito área apresentou uma tendência crescente, indicando que houve mudanças na produção da cana-de-açúcar oriundas de um incremento na área plantada no Mato Grosso do Sul. Esse aumento, segundo informações da Biosul (2012), ocorreu em áreas de pastagens subaproveitadas da pecuária, não interferindo na área de produção das demais culturas agrícolas do estado, como da soja, do milho, entre outros produtos. $\mathrm{O}$ efeito mostrou-se mais significativo nas safras de 2006/2007 a 2011/2012, registrando um incremento de $108 \%$ no período. O efeito área também registrou oscilações negativas. De acordo com o Relatório de safras da Conab, de 2005, na safra 2005/2006, as baixas precipitações e as chuvas inesperadas atrapalharam o desenvolvimento dos canaviais no Mato Grosso do Sul. As safras 2000/2001 e 2002/2003 também registraram quebra e apresentaram índices negativos (vide Figura 5). As lavouras de soja e milho tiveram resultados negativos para o efeito área, indicando que não houve alterações na produção oriundas de mudanças na área plantada (Figura 5).

A Tabela 1 apresenta o efeito substituição de uma cultura em detrimento de outra entre as safras de 1990 a 2011, desse modo, para que uma cultura aumente sua produção, é necessário que outra diminua sua área. As variáveis que apresentaram o efeito substituição negativo perderam espaço para aquelas culturas que apresentaram efeito positivo (FOREST et al., 2014). 
Tabela 1 - Valores do efeito substituição das culturas em Mato Grosso do Sul

\begin{tabular}{l|c|l}
\hline \multicolumn{1}{c|}{ Variáveis } & Efeito substituição & \multicolumn{1}{c}{ Descrição } \\
\hline Cana & 343,80 & efeito substituição cultura cana-de-açúcar \\
Soja & $-452,54$ & efeito substituição cultura soja \\
Milho & 461,94 & efeito substituição cultura milho \\
Outras & $-353,20$ & efeito substituição cultura outras \\
\hline
\end{tabular}

Fonte: elaborada pelos autores com base em dados da Conab.

As culturas de cana-de-açúcar e milho apresentaram efeito substituição positivo, 343,80 e 461,94, respectivamente, significando que elas aumentaram sua produção em áreas destinadas a outras culturas, como a do soja e a do arroz e do feijão, que apresentaram um efeito de substituição negativo, -452,54 e -353,20, respectivamente.

Do mesmo modo, Oliveira, Neder e Almeida Filho (2010) fornecem indícios de que no estado de Minas Gerais a cana-de-açúcar é fortemente propícia a substituir outros cultivos, inclusive o de soja. Enquanto que Abdala e Ribeiro (2011) reconhecem que esse processo de substituição deve ser minunciosamente analisado, segundo a formação e concentração de cada cultivo nas regiões estudadas, trabalhando com microrregiões, como realizado no estado de Goiás.

Apesar de dados semelhantes encontrados nos estudos citados, é de se convir que as culturas de soja e milho, em especial no estado de Mato Grosso do Sul, são substitutas devido aos métodos de plantio e de colheita praticados, isto é, mutuamente são utilizadas para rotação de plantio dentro do mesmo período anual.

E por isso deve ser feita uma ressalva aos valores obtidos pelo efeito substituição, pois, quando um produto tiver valor positivo/negativo não quer dizer rigorosamente que o produto substitua/seja substituído por outras culturas, mas que apenas apresenta uma taxa de crescimento maior/menor que a taxa global (y) (FOREST et al., 2014).

O efeito escala é dado pela variação na área do produto apenas pela alteração do tamanho do sistema, mantendo inalterada sua participação. Se os valores forem positivos, representam uma tendência de expansão das culturas; se forem negativos, representam uma tendência de diminuição na produção das culturas dentro do sistema. Os valores encontrados no efeito escala para cada produto mostram como seria o comportamento de cada cultura se a ampliação ou a contração da área total fossem distribuídas de modo uniforme entre elas (SANTOS; FARIA; TEIXEIRA, 2008). 
Tabela 2 - Valores do efeito escala das culturas em Mato Grosso do Sul

\begin{tabular}{l|c|l}
\hline \multicolumn{1}{c|}{ Variável } & Efeito escala & \multicolumn{1}{c}{ Descrição } \\
\hline Cana & 84,10 & efeito escala cultura cana-de-açúcar \\
Soja & 1254,44 & efeito escala cultura soja \\
Milho & 445,76 & efeito escala cultura milho \\
Outras & 426,20 & efeito escala cultura outras \\
\hline
\end{tabular}

Fonte: elaborada pelos autores com base em dados da Conab.

O efeito escala observado (Tabela 2) mostra que todas as culturas obtiveram uma tendência de expansão no período observado. A cana-de-açúcar foi a que apresentou o menor valor dentre as demais. Abdala e Ribeiro (2011) destacam a realidade da permuta entre culturas em vários estados brasileiros, o que reconfigura a composição da atividade agrícola da região. Entretanto, a expansão equilibrada das culturas se dá, muitas vezes, por meio de outros processos, e não exatamente o da substituição, por exemplo, pelo desmatamento ou por áreas antes destinadas à pecuária.

O efeito produtividade apresentou pequenas oscilações, acompanhando na maior parte do período as variações na produção total de cana. Conforme observou-se na Figura 5, a produtividade da cana-de-açúcar apresentou um efeito cíclico com picos positivos e negativos entre as safras. A oscilação verificada nesse efeito se deu em grande parte por quebras de safra oriundas da sazonalidade das culturas agrícolas.

Pode-se atribuir os ganhos de produtividade à adoção da colheita mecanizada no processo produtivo da cana-de-açúcar. Até o ano de 2012, cerca de $85 \%$ da colheita na região Centro-Sul era feita de modo mecanizado. O estado do Mato Grosso do Sul teve $95 \%$ do total de suas áreas colhidas com cana-de-açúcar de forma mecanizada.

Braunbeck e Magalhães (2010) e Moraes (2007) explicam que não apenas o solo plano e favorável ao uso de maquinário, mas também mudanças no comportamento institucional, quanto à exploração do trabalho e ambiente, impulsionaram muitos estados a mudar a forma de colheita da cana. No Mato Grosso do Sul, tais procedimentos estão previstos na Lei $\mathrm{n}^{\mathrm{0}} 3.357 / 2007$.

O efeito também mostrou uma perda de produtividade em algumas safras, destacadamente as de 1999/2000 e 2010/2011. Isso possivelmente reflete a decisão do governo brasileiro em manter os preços dos combustíveis fósseis estabilizados. Além disso, fatores climáticos desfavoráveis foram os principais causadores das quebras de safra enfrentadas pela cana-de-açúcar nesses períodos. 
Para a cana-de-açúcar, o efeito localização não indicou mudanças positivas na localização de suas lavouras, dessa maneira, pode-se concluir que a produção de cana não está se desenvolvendo em áreas destinadas a outras culturas agrícolas. Sendo assim, a produção de alimentos, tais como a soja e o milho, não foi afetada pela expansão produtiva da cana-de-açúcar no Mato Grosso do Sul. O efeito pode ser comprovado por meio do resultado do efeito substituição, analisado juntamente com o efeito área.

\section{Considerações finais}

A análise do método shift-share, utilizado neste trabalho, permitiu apontar a graduação na expansão da produção da cana-de-açúcar no Mato Grosso do Sul e indicou que o efeito área foi o principal fator de expansão da produção de cana-de-açúcar no estado. Esse efeito explica que os incrementos na área plantada com cana-de-açúcar determinaram de maneira positiva a produção da cultura no estado.

O aumento na área plantada no estado do Mato Grosso do Sul chegou a ser de $110 \%$ no período em análise, o que mostrou que o efeito área encontrado foi coerente com a expansão da área plantada com cana-de-açúcar no estado.

O efeito substituição mostrou que a cana-de-açúcar, assim como o milho, ganhou espaço no Mato Grosso do Sul, sendo, portanto, substituinte de outras culturas no estado, como a soja e outras culturas analisadas, que apresentaram um efeito negativo. Contudo, é importante ressaltar que o efeito substituição não indica rigorosamente que determinada cultura substitui ou foi substituída por outra, como se pode observar, a soja e o milho têm a mesma área de plantio no Mato Grosso do Sul, porém são cultivadas em safras diferentes, enquanto a safra de verão se destina à cultura da soja, a entressafra ou safrinha é destinada ao cultivo do milho.

Diante dos resultados deste trabalho, pode-se concluir que a produção da cana-de-açúcar não substitui as demais culturas agrícolas no Mato Grosso do Sul, o que se observou foi um crescimento em maior nível que as demais, principalmente no quesito área.

Os demais efeitos não se mostraram fatores explicativos para o aumento da produção de cana-de-açúcar no estado. O efeito produtividade ficou próximo de zero, apresentando um efeito cíclico de pequena magnitude. O efeito localização geográfica apresentou valores negativos, indicando que não houve mudança na localização das lavouras no estado. 


\title{
Culture sugar production expansion in Mato Grosso do Sul: an analysis model from shift-share
}

\begin{abstract}
New aim for ethanol and increased sugar consumption in the world, led to a considerable expansion in the production of culture of sugar cane. The aim this worl is to analyze the culture of sugar cane production expansion in the state of Mato Grosso do Sul, Brazil, between 1990 and 2011. The method used was the shift-share. The results show that the main cause of the expansion of culture of sugar cane area in the state was in effect. The substitution effect had a positive value to the culture of sugar cane, confirming that culture has gained ground in state. The effect-productivity remained close to zero, indicating significant productivity gains. The geographical location effect showed a downward trend, indicating that there was no change in the location of culture sugar cane sugar plantation

Keywords: Culture sugar cane. Mato Grosso do Sul. Production expansion. Shift-share.

\section{La expansión en la producción de la canã en el estado de Mato Grosso do Sul: el analisis del metodo shift-share}

\section{Resumen}

Nuevas perspectivas para el etanol y el aumento del consumo de azúcar en el mundo, dio lugar a una considerable expansión en la producción de caña. En este sentido, el propósito de este artículo es analizar la expansión de la producción de caña de azúcar en el estado de Mato Grosso do Sul, Brasil, entre 1990 y 2011. El método utilizado fue el shift-share. Los resultados muestran que la causa principal de la expansión de la producción de la caña de azúcar estaba en el efecto del área de estado. El efecto de sustitución tenía un valor positivo para la cultura de la caña de azúcar, lo que confirma que la cultura ha ganado terreno en el estado. El efecto en la productividad se mantuvo cercano a cero, lo que indica no hay ganancias de productividad importantes. El efecto ubicación geográfica mostró una tendencia a la baja, lo que indica que no hubo ningún cambio en la ubicación de los cultivos de caña.
\end{abstract}

Palabras clave: Caña. Expansión de la producción. Mato Grosso do Sul. Shift-share. 


\section{Referências}

ABDALA, Klaus de Oliveira; RIBEIRO, Francis Lee. Análise dos impactos da competição pelo uso do solo no estado de Goiás durante o período 2000 a 2009 provenientes da expansão do complexo sucroalcooleiro. Revista Brasileira de Economia, Rio de Janeiro, v. 65, n. 4, p. 373-400, 2011.

BACCARIN, José Giacomo; GEBARA, José Jorge; BORGES JÚNIOR, Júlio Cesar. Expansão canavieira e ocupação formal em empresas sucroalcooleiras do Centro-Sul do Brasil, entre 2007 e 2009. 2011. Disponível em: <http://www.scielo.br/scielo.php?pid=S0103-20032011 000200010\&script=sci_arttext>. Acesso em: 31 mar. 2013.

BACHA, Carlos José Caetano. Economia e política agrícola no Brasil. 2. ed. São Paulo: Atlas, 2012.

BIOSUL. Estimativa de safra 2012/2013. 2012. Disponível em: <http://www.biosulms.com.br/ arqv/coletiva_primeira_estimativa_12-13.pdf>. Acesso em: 13 maio 2014.

BRASIL. Ministério da Agricultura, Pecuária e Abastecimento. Produção integrada no Brasil. 2008. Disponível em: <http://www.agricultura.gov.br/arq_editor/file/Desenvolvimento_Sustentavel/Produ\%C3\%A7\%C3\%A30\%20Integrada/PI_Brasil.pdf>. Acesso em: 19 jun. 2013.

BRAUNBECK, O. A.; MAGALHÃES P. S. G. Avaliação tecnológica da mecanização da cana-de-açúcar, P\&D para produtividade e sustentabilidade. São Paulo: Blucher, 2010.

COMPANHIA NACIONAL DE ABASTECIMENTO. Acompanhamento de safra brasileira: cana-de-açúcar. Safra 2011/2012. 2011. Disponível em: <httphttp://www.conab.gov.br/OlalaCMS/uploads/arquivos/a5c419405d6 9bbbb8dbf8e4e191fa7ae>. Acesso em: 19 abr. 2014.

. Acompanhamento de safra brasileira: cana-de-açúcar. Safra 2013/2014. 2013. Disponível em: <http://www.conab.gov.br/OlalaCMS/uploads/arqui vos/13_04_09_10_2 9_31_boletim_ cana_portugues_abril_2013_1o_lev.pdf>. Acesso em: 29 jul. 2013.

Séries históricas. Disponível em: <http://www.conab.gov.br/conteudos.php $? \mathrm{a}=1252 \& \mathrm{t}=\&$ Pagina_objcmsconteudos=2\#A_objcmsconteudos $>$. Acesso em: 5 mar. 2014.

FEDERAÇÃO DA AGRICULTURA E PECUÁRIA DO MATO GROSSO DO SUL. Balanço 2013 e perspectivas 2014. 2013. Disponível em: <http://famasul.com. br/public/area-produtor/794-relatorio-de-pesquisa-mip-matriz-insumo-produto.pdf $>$. Acesso em: 14 maio 2014.

FERREIRA NETO, J. Competitividade da produção de cana-de-açúcar no Brasil. Dissertação (Mestrado em Economia Aplicada) - Universidade Federal de Viçosa, Viçosa, 2005.

FOREST, Rafael et al. Segurança alimentar e a relação com a expansão do programa de biocombustíveis. Revista de Política Agrícola, Brasília, v. 23, n. 3, 2014.

GALETE, Rinaldo Aparecido. Uma aplicação do método estrutural-diferencial Modificado para a Microrregião de Maringá (PR) frente à economia paranaense no período de 1994 a 2008. Estudos do CEPE, n. 33, p. 55-92, 2011.

GUIMARÃES, Lucy Teixeira; TURETTA, Ana Paula Dias; COUTINHO, Heitor Luiz da Costa. Uma proposta para avaliar a sustentabilidade da expansão do cultivo da cana-de-açúcar no estado do Mato Grosso do Sul. 2010. Disponível em: <http://www.scielo.br/scielo.php?script=sciart text\&pid=S198245132010000200007\&lang=pt>. Acesso em: 12 mar. 2013. 
MARJOTTA-MAISTRO, M. C. Ajustes nos mercados de álcool e gasolina no processo de desregulamentação. Tese (Doutorado em Economia Aplicada) - Universidade de São Paulo/Esalq, Piracicaba, 2002.

MENDES, J. T. G.; PADILHA JÚNIOR, J. J. Agronegócio: uma abordagem econômica. São Paulo: Pearson Prentice Hall, 2007.

MICHELLON, Ednaldo; SANTOS, Ana Aracelly Lima; RODRIGUES, Juliano Ricardo Alves. Breve descrição do Proálcool e perspectivas futuras para o etanol produzido no Brasil. In: CONGRESSO DA SOCIEDADE BRASILEIRA DE ECONOMIA, ADMINISTRAÇÃO E SOCIOLOGIA RURAL (SOBER), 46, 2008. Anais... Rio Branco, Acre, 2008.

MORAES, Marcia A. F. D.; SHIKIDA, Pery F. A. Agroindústria canavieira no Brasil: evolução, desenvolvimento e desafios. São Paulo: Atlas, 2002.

MORAES, Márcia A. F. D. O mercado de trabalho da agroindústria canavieira: desafios e oportunidades. Revista Economia Aplicada, Ribeirão Preto, v. 11, n. 4, p. 605-619, 2007.

OLIVEIRA, Izabel Cristina Carvalho de; NEDER, Henrique Dantas; ALMEIDA FILHO, Niemeyer. Impactos sociais da expansão do Programa de Biocombustíveis sobre o estado de Minas Gerais. In: SEMINÁRIO SOBRE A ECONOMIA MINEIRA, 14, 2010. Anais... Belo horizonte: Cedeplar, 2010.

PADRÃO, Glaucia de Almeida; GOMES, Marilia Fernandes Maciel; GARCIA, João Carlos. Determinantes estruturais do crescimento da produção brasileira de grãos por estados da federação: 1989/1990/1991 e 2006/2007/2008. Viçosa: Universidade Federal de Viçosa, 2012.

ROLIM, C. F. C. Restruturação produtiva, mundialização e novas territorialidades: um novo programa para os cursos de economia regional e urbana. Curitiba, 1999. Disponível em: <http:// www.economia.ufpr.br>. Acesso em: 20 jun. 2013.

SANTOS, Fernando Antônio Agra; FARIA, Roberto Araújo de; TEIXEIRA, Erly Cardoso. Mudança da composição agrícola em duas regiões de Minas Gerais. Revista de Economia e Sociologia Rural, Brasília, v. 46, n. 3, p. 579-595, 2008.

SZMRECSÁNYI, T. O planejamento da agroindústria canavieira do Brasil (1930-1975). São Paulo: Hucitec/Unicamp, 1979.

SILVA, E. P da. A evolução da produção do álcool combustível e a região norte do Brasil de 1975 à 2005. 2006. 75 f. Monografia (Graduação em Ciências Econômicas) - Universidade Estadual de Maringá, Maringá, 2006.

SIMÕES, Rodrigo. Métodos de análise regional e urbana: diagnóstico aplicado ao planejamento. Belo Horizonte: Cedeplar/UFMG, 2005.

SHIKIDA, Pery F. A; BACHA, Carlos J. Caetano. Evolução da agroindústria canavieira brasileira. Universidade Estadual do Oeste do Paraná, 1999. Disponível em: <http://bibliotecadigital. fgv.br/ojs/index.php/rbe/article/viewFile/746/1740>. Acesso em: 15 maio 2014.

THEODORO, Antônio Donisete. Expansão da cana de açúcar no Brasil: ocupação da cobertura vegetal do cerrado. 2011. 62 f. Trabalho de Conclusão de Curso (Graduação em Tecnologia em Biocombustíveis) - Faculdade de Tecnologia de Araçatuba, Araçatuba, 2011.

UNIÃO DA INDÚSTRIA DE CANA-DE-AÇÚCAR. Acompanhamento quinzenal. Posição até 16/06/2014. Disponível em: <http://www.unicadata.com.br/listagem.php?idMn=63>. Acesso em: 20 jun. 2014. 
Balanço 2012. Principais ações e projetos. 2012. Disponível em: <http://www.unica.com. br/download.php?idSecao=17\&id=7073337>. Acesso em: 2 abr. 2014.

Relatório final da Safra 2010/2011 Região Centro-Sul. Disponível em: <http://www.unicadata.com.br/listagem.php?idMn=36>. Acesso em: 19 abr. 2014.

Relatório final da safra 2011/2012 Região Centro-Sul. Disponível em: <http://www.unicadata.com.br/historico-de-producao-e-moagem.php?idMn=32\&tipoHistorico=4>. Acesso em: 1 abr. 2013. 